\title{
Transport Properties of Statins by Organic Anion Transporting Polypeptide 1A2 and Regulation by Transforming Growth Factor- $\beta$ Signaling in Human Endothelial Cells ${ }^{[\Phi}$
}

\author{
Patrick T. Ronaldson, Hrvoje Brzica, Wazir Abdullahi, Bianca G. Reilly, \\ and Thomas P. Davis \\ Department of Pharmacology, College of Medicine, University of Arizona, Tucson, Arizona
}

Received August 3, 2020; accepted November 3, 2020

\begin{abstract}
Our in vivo rodent studies have shown that organic anion transporting polypeptide (Oatp) 1a4 is critical for blood-to-brain transport of statins, drugs that are effective neuroprotectants. Additionally, transforming growth factor- $\beta$ (TGF- $\beta$ ) signaling via the activin receptor-like kinase 1 (ALK1) receptor regulates Oatp1a4 functional expression. The human ortholog of Oatp1a4 is OATP1A2. Therefore, the translational significance of our work requires demonstration that OATP1A2 can transport statins and is regulated by TGF- $\beta /$ ALK1 signaling. Cellular uptake and monolayer permeability of atorvastatin, pravastatin, and rosuvastatin were investigated in vitro using human umbilical vein endothelial cells (HUVECs). Regulation of OATP1A2 by the TGF- $\beta$ /ALK1 pathway was evaluated using bone morphogenetic protein 9 (BMP-9), a selective ALK1 agonist, and LDN193189, an ALK1 antagonist. We showed that statin accumulation in HUVECs requires OATP1A2-mediated uptake but is also affected by efflux transporters (i.e., P-glycoprotein, breast cancer resistance protein). Absorptive flux (i.e., apical-to-basolateral) for all statins was higher than secretory flux (i.e., basolateral-toapical) and was decreased by an OATP inhibitor (i.e., estrone-3sulfate). OATP1A2 protein expression, statin uptake, and cellular
\end{abstract}

monolayer permeability were increased by BMP-9 treatment. This effect was attenuated in the presence of LDN193189. Apical-to-basolateral statin transport across human endothelial cellular monolayers requires functional expression of OATP1A2, which can be controlled by therapeutically targeting TGF$\beta / A L K 1$ signaling. Taken together with our previous work, the present data show that OATP-mediated drug transport is a critical mechanism in facilitating neuroprotective drug disposition across endothelial barriers of the blood-brain barrier.

\section{SIGNIFICANCE STATEMENT}

Transporter data derived from rodent models requires validation in human models. Using human umbilical vein endothelial cells, this study has shown that statin transport is mediated by OATP1A2. Additionally, we demonstrated that OATP1A2 is regulated by transforming growth factor- $\beta /$ activin receptor-like kinase 1 signaling. This work emphasizes the need to consider endothelial transporter kinetics and regulation during preclinical drug development. Furthermore, our forward-thinking approach can identify effective therapeutics for diseases for which drug development has been challenging (i.e., neurological diseases).

\section{Introduction}

A principal goal of pharmacotherapy is delivery of drugs to their targets at efficacious concentrations. This objective is challenging in the context of neurologic diseases because of the blood-brain barrier (BBB). The primary interface between the $\mathrm{BBB}$ and circulation is the microvascular endothelium, which expresses transport proteins, such as organic anion

This work is funded by grants from the National Institutes of Health National Institute of Neurologic Diseases and Stroke [R01-NS084941] (to P.T.R.) and the American Heart Association (19TPA34910113) to P.T.R. as well as by a grant from the National Institute on Drug Abuse [R01-DA051812] (to T.P.D. and P.T.R.)

The authors have no conflicts of interest to declare.

https://doi.org/10.1124/jpet.120.000267.

S This article has supplemental material available at jpet.aspetjournals.org. transporting polypeptides (OATPs in humans; Oatps in rodents), that facilitate CNS drug delivery (Ronaldson and Davis, 2013; Abdullahi et al., 2017b). Expression of Oatp1a4 has been reported in rat brain microvessels (Ronaldson et al., 2011; Thompson et al., 2014; Abdullahi et al., 2017a, 2018; Brzica et al., 2018), rat retinal capillary endothelium (Akanuma et al., 2013), and primary rat brain endothelial cells (Harati et al., 2013). This transporter plays a functional role in CNS drug disposition as evidenced by in situ perfusion studies (Ronaldson et al., 2011; Thompson et al., 2014; Abdullahi et al., 2017a), pharmacokinetic experiments in female Naval Medical Research Institute mice (Römermann et al., 2017), and transport experiments in Oatp1a4 null mice (Ose et al., 2010). These observations provide a strong basis for expanded validation of Oatps for CNS delivery of therapeutics.

ABBREVIATIONS: ALK1, activin receptor-like kinase 1; BBB, blood-brain barrier; BCRP, breast cancer resistance protein; BMP-9, bone morphogenetic protein 9; CNS, central nervous system; CsA, cyclosporine A; DNP, dinitrophenol; E3S, estrone-3-sulfate; FEX, fexofenadine; FTC, fumitremorgin C; HBSS, Hanks' balanced salt solution; HUVEC, human umbilical vein endothelial cell; IR, influx ratio; NAR, naringin; OATP, organic anion transporting polypeptide; Papp, apparent permeability coefficient; Papp A-B, apparent permeability coefficient, apical-to-basolateral direction; P-gp, P-glycoprotein; TEER, transendothelial electrical resistance; TGF- $\beta$, transforming growth factor- $\beta$. 
Our recent work has focused on examination of targeting Oatp1a4 for brain delivery of 3-hydroxyl-3-methylglutaryl coenzyme A reductase inhibitors (i.e., statins). This concept is important for advancement of strategies to treat ischemic stroke. Indeed, 95\% of published preclinical studies between 1990 and 2018 on novel neuroprotective drugs for stroke showed positive outcomes; however, none of these compounds have attained clinical success in a phase III trial (Shi et al., 2018). In contrast, statin administration is associated with a lower degree of physical disability (Ishikawa et al., 2016; Malhotra et al., 2019) or reduced risk of recurrent stroke (Lee et al., 2017). Our work has demonstrated that Oatp1a4 can facilitate CNS delivery of both hydrophilic statins (i.e., pravastatin) and hydrophobic statins (i.e., atorvastatin) (Abdullahi et al., 2018). These studies corroborate observations from Oatp1a4(-/-) mice that have shown reduced bloodto-brain transport of statins as compared with wild-type controls (Ose et al., 2010). We have also shown for the first time that Oatp1a4 functional expression is directly regulated by transforming growth factor- $\beta$ (TGF- $\beta$ ) signaling at the brain microvascular endothelium (Abdullahi et al., 2017a, 2018). Specifically, our work on the TGF- $\beta$ /activin receptorlike kinase 1 (ALK1) pathway has shown that this signaling cascade can be targeted pharmacologically to control Oatpmediated small-molecule drug delivery (Abdullahi et al., 2018). Indeed, a detailed understanding of Oatp regulation and transport properties is critical to continued optimization of statins as stroke therapeutics.

The primary drug transporting OATP isoform in human endothelial cells is OATP1A2, the human ortholog of Oatp1a4 (Bronger et al., 2005; Lee et al., 2005). Disparities in drug transport properties between OATP1A2 and Oatp1a4 have been reported in the literature. For example, studies in human embryonic kidney cells stably expressing Oatp1a4 and in Oatp1a4(-/-) mice reported lack of transport of antimigraine triptan medications (Liu et al., 2015). In contrast, transport of zolmitriptan was observed in Madin-Darby canine kidney cells stably expressing OATP1A2 (Liu et al., 2015) and in an OATP1A2 knock-in mouse model (Sano et al., 2018), thereby providing evidence for substrate differences between OATP1A2 and Oatp1a4. The work of Liu et al. emphasized to us a critical need to evaluate statin OATP1A2 transport properties. OATP-mediated transport of currently marketed statins has been shown in cell lines that stably express OATP1A2 (Mandery et al., 2010; Navrátilová et al., 2018) or in transfected Xenopus oocyte systems (Shirasaka et al., 2010); however, neither OATP-mediated statin cellular uptake nor monolayer permeability has been studied in detail using an in vitro system comprising nontransfected human endothelial cells. Using a preplanned study design, we addressed this critical issue in human umbilical vein endothelial cells (HUVECs) by testing the hypothesis that OATP1A2 is a critical transporter in the uptake transport of atorvastatin, pravastatin, and rosuvastatin. An added strength of the HUVEC model is that it also expresses efflux transporters [i.e., P-glycoprotein (P-gp), breast cancer resistance protein (BCRP)], thereby providing the ability to assess OATP1A2mediated transport in a more physiologically relevant multitransporter environment. Here, we demonstrate that all three statins are OATP1A2 substrates and that their uptake and monolayer permeability are also determined by P-gp and/or BCRP. We also show, for the first time, that activation of
TGF- $\beta$ /ALK1 signaling with the ALK1 agonist bone morphogenetic protein 9 (BMP-9) can increase HUVEC uptake and monolayer permeability of atorvastatin, pravastatin, and rosuvastatin.

\section{Materials and Methods}

Materials. $\left[{ }^{3} \mathrm{H}\right]$ Atorvastatin $(20 \mathrm{Ci} / \mathrm{mmol}),\left[{ }^{3} \mathrm{H}\right]$ pravastatin $(15 \mathrm{Ci} /$ $\mathrm{mmol})$, and $\left[{ }^{3} \mathrm{H}\right]$ rosuvastatin $(10 \mathrm{Ci} / \mathrm{mmol})$ were purchased from American Radiolabeled Chemicals, Inc. (St. Louis, MO). $\left[{ }^{14} \mathrm{C}\right]$ Sucrose $(0.5 \mathrm{Ci} / \mathrm{mmol}$ ) was obtained from PerkinElmer (Hopkinton, MA). BMP9 was purchased from R\&D Systems (Minneapolis, MN). Atorvastatin, cyclosporine A (CsA), dinitrophenol (DNP), estrone-3-sulfate (E3S), fexofenadine (FEX), fumitremorgin C (FTC), LDN193189, naringin (NAR), pravastatin, rosuvastatin, sodium azide $\left(\mathrm{NaN}_{3}\right)$, the mouse monoclonal P-gp C219 antibody, and the mouse monoclonal anti- $\beta$ actin antibody were obtained from Millipore-Sigma (St. Louis, MO). GF120918 and PSC833 were acquired from Tocris Bioscience (Minneapolis, MN). The rabbit polyclonal OATP1A2 antibody (ab221804), the rabbit polyclonal OATP1B1 antibody (ab224610), the rabbit polyclonal OATP1B3 antibody (ab224064), the rabbit polyclonal OATP2B1 antibody (ab203215), the rabbit monoclonal BCRP antibody (ab207732), and the rabbit monoclonal ALK1 antibody (ab108207) were all purchased from Abcam (Cambridge, MA). All cell culture reagents were purchased from ThermoFisher Scientific (Carlsbad, CA) unless otherwise stated.

Cell Culture. HUVECs were kindly provided by Dr. Gregory Bix (Tulane University, New Orleans, LA). All cell culture flasks and assay plates were precoated with gelatin $(1 \mathrm{mg} / \mathrm{ml}$; ThermoFisher Scientific Inc., Waltham, MA) prior to plating of HUVECs. Gelatin was used to ensure endothelial cell attachment to all tissue culture flasks and plates that were used in this study. HUVECs were grown in M199 medium supplemented with fetal bovine serum (10\%), $1 \times$ antibiotic/ antimycotic reagent, heparin $(50 \mu \mathrm{g} / \mathrm{ml}$; Sigma-Aldrich), and endothelial cell growth supplement $(400 \mu \mathrm{g} / \mathrm{ml})$, which consisted of alpha fibroblast growth factor, basic fibroblast growth factor, and various attachment/signaling molecules. All cells were maintained at $37^{\circ} \mathrm{C}$ in a humidified $5 \% \mathrm{CO}_{2}$ environment with fresh medium replaced every 2 to 3 days. Cells were subcultured with $0.25 \%$ trypsinethylenediaminetriacetic acid (EDTA) upon reaching 95\% confluence.

The human cervical carcinoma cell line (HeLa) was used as a positive control for OATP1A2, P-gp, and BCRP protein expression studies. HeLa cells were cultured and maintained in Dulbecco's modified Eagle's medium (4 mM L-glutamine and $25 \mathrm{mM}$ glucose) supplemented with fetal bovine serum (10\%) and penicillin/streptomycin (1\%). Confluent cultures were subcultured with $0.25 \%$ trypsinEDTA.

The hepatocellular carcinoma cell line (HepG2) was used as a positive control for OATP isoform expression experiments. HepG2 cells were cultured and maintained in Minimum Essential Medium supplemented with fetal bovine serum (10\%). As with HeLa cells, confluent cultures were subcultured with $0.25 \%$ trypsin-EDTA.

Western Blot Analysis. Western blotting was performed as previously described (Ronaldson and Bendayan, 2006; Abdullahi et al., 2017a), with a few modifications. Briefly, whole cell lysates from HUVECs, HeLa cells, or HepG2 cells were prepared by exposing the cells to $2.0 \mathrm{ml}$ of modified radioimmunoprecipitation buffer [50 mM Tris-HCl, $\mathrm{pH} 7.4,150 \mathrm{mM} \mathrm{NaCl}, 1.0 \mathrm{mM}$ EGTA, $1.0 \mathrm{mM}$ sodium-o-vanadate, $1 \% \quad(\mathrm{v} / \mathrm{v})$ Nonidet P-40, $0.25 \% \quad(\mathrm{~m} / \mathrm{v})$ sodium deoxycholate, $0.1 \%$ sodium dodecyl sulfate, $200 \mu \mathrm{M}$ phenylmethylsulfonyl fluoride, and $0.1 \%$ protease inhibitor cocktail (Sigma-Aldrich)]. The cells were then gently rocked for 15 minutes at $4^{\circ} \mathrm{C}$ to permit lysis. Cell suspensions were collected and centrifuged at $3000 \mathrm{~g}$ for 15 minutes at $4^{\circ} \mathrm{C}$ to remove cellular debris. The supernatant was then collected and centrifuged at $100,000 \mathrm{~g}$ for 1 hour at $4^{\circ} \mathrm{C}$. The resultant pellet was resuspended in $10 \mathrm{mM}$ Tris buffer, $\mathrm{pH} 8.8$, and stored at $-20^{\circ} \mathrm{C}$ until further use. Protein concentration of the cell lysates was determined via Bradford's protein assay. 
For Western blotting, cell lysates were heated at $37^{\circ} \mathrm{C}$ for 30 minutes under reducing conditions [i.e., 2.5\% (v/v) 2-mercaptoethanol (SigmaAldrich)] in $1 \times$ Laemmli sample buffer (Bio-Rad, Hercules, CA) for OATP, P-gp, or BCRP detection. For ALK1 detection, the samples were heated at $95^{\circ} \mathrm{C}$ for 10 minutes under nonreducing conditions in $1 \times$ Laemmli sample buffer. All cell lysate samples were resolved on a 4\%-12\% Criterion XT Bis-Tris polyacrylamide gel (Bio-Rad). After SDS-PAGE and transfer, polyvinylidene difluoride (PVDF) membranes were blocked for 1 hour in Superblock TBS blocking buffer (ThermoFisher) and then incubated overnight at $4^{\circ} \mathrm{C}$ with primary anti-OATP1A2 antibody (1:500 dilution), anti-OATP1B1 antibody (1: 1000 dilution), anti-OATP1B3 antibody (1:1000 dilution), antiOATP2B1 antibody (1:500 dilution), primary anti-P-gp C219 antibody (1:1000 dilution), primary anti-BCRP antibody (1:500 dilution), primary anti-ALK1 antibody (1:500 dilution), or primary anti- $\beta$-actin (1:500 dilution). The blots were then incubated for 1 hour with corresponding horseradish peroxidase-conjugated anti-rabbit (1: $40,000)$ or anti-mouse $(1: 500,000)$ secondary antibody (Jackson ImmunoResearch, West Grove, PA). Control Western blot experiments to confirm antibody specificity were performed in the presence of secondary antibody only (i.e., absence of primary antibody) and using nontransfected HEK293 cells that do not express detectable levels of OATP transporters. Membranes were developed using enhanced chemiluminescence (Super Signal West Pico; ThermoFisher). Bands were quantitated using ImageJ software (Wayne Rasband, Research Services Branch, National Institute of Mental Health, Bethesda, MD) and normalized to $\beta$-actin.

Transport Experiments in HUVECs. For cellular uptake experiments, cells were seeded into 48 -well plates with a cell density of $2 \times 10^{4}$ cells $/ \mathrm{cm}^{2}$. All transport experiments were performed by using Hanks' balanced salt solution (HBSS) containing $1.3 \mathrm{mM} \mathrm{CaCl}_{2}$, $0.49 \mathrm{mM} \mathrm{MgCl}_{2}, 0.41 \mathrm{mM} \mathrm{MgSO}_{4}, 5.3 \mathrm{mM} \mathrm{KCl}, 0.44 \mathrm{mM} \mathrm{KH} \mathrm{PO}_{4}$, $138 \mathrm{mM} \mathrm{NaCl}, 0.34 \mathrm{mM} \mathrm{Na}_{2} \mathrm{HPO}_{4}$, and $5.6 \mathrm{mM}$ D-glucose. The buffer

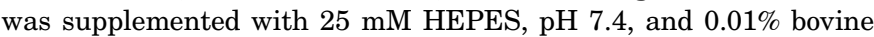
serum albumin (BSA) to reduce the binding of radiolabeled compounds to the glass and plastic. Throughout this paper, this HBSS buffer is referred to as transport buffer. Confluent monolayers of HUVECs were preincubated with transport buffer $\left(\mathrm{pH} \mathrm{7.4)}\right.$ at $37^{\circ} \mathrm{C}$ for 15 minutes and then incubated in transport buffer containing $0.1 \mu \mathrm{Ci} / \mathrm{ml}\left[{ }^{3} \mathrm{H}\right]$ atorvastatin, $\left[{ }^{3} \mathrm{H}\right]$ pravastatin, or $\left[{ }^{3} \mathrm{H}\right]$ rosuvastatin. Buffer containing radiolabeled compounds was supplemented with the equivalent unlabeled compound to achieve a desired concentration of $10 \mu \mathrm{M}$. Published $\mathrm{K}_{\mathrm{M}}$ values for OATP-mediated statin transport are in the low to mid micromolar range (Ho et al., 2006; Lau et al., 2007; Mao et al., 2018). We purposely selected $10 \mu \mathrm{M}$ for all of our transport assays to use an equimolar and nonsaturating statin concentration that is within range of these $\mathrm{K}_{\mathrm{M}}$ values and to allow for comparisons in transport properties between atorvastatin, pravastatin, and rosuvastatin. To evaluate the effect of an OATP, P-gp, or BCRP transport inhibitor, a specific concentration of the inhibitor was added both to the preincubation buffer and to the radioactive transport buffer. To study the role of TGF- $\beta$ /ALK1 signaling on OATPmediated statin uptake, HUVECs were incubated with BMP-9 $(0.1$ or $1 \mathrm{nM}$; $0.1 \%$ DMSO final concentration) for 6 hours prior to transport experiments. To evaluate specificity of BMP-9 at the ALK1 receptor, cells were incubated with LDN193189 $(10 \mu \mathrm{M})$ for 1 hour before addition of BMP-9 to the same chamber. These concentrations and exposure time points for BMP-9 and LDN193189 were selected to maintain consistency with our previous work (Abdullahi et al., 2017a, 2018). Specifically, we determined that a dose of $0.1 \mu \mathrm{g} / \mathrm{kg}$ is

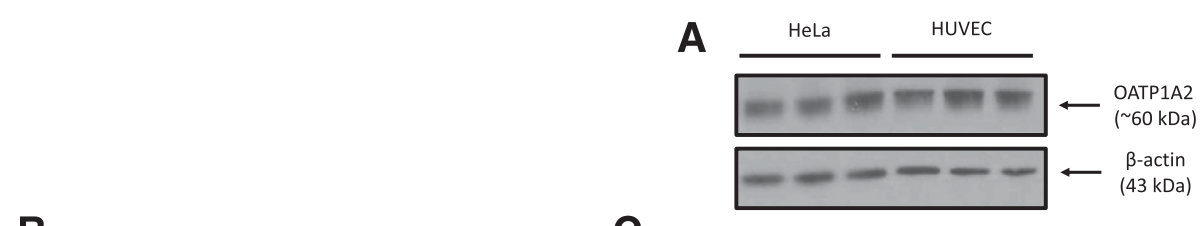

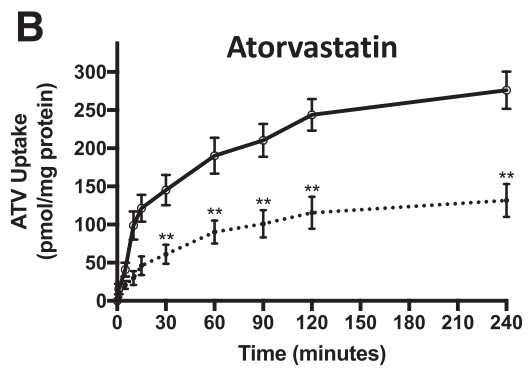

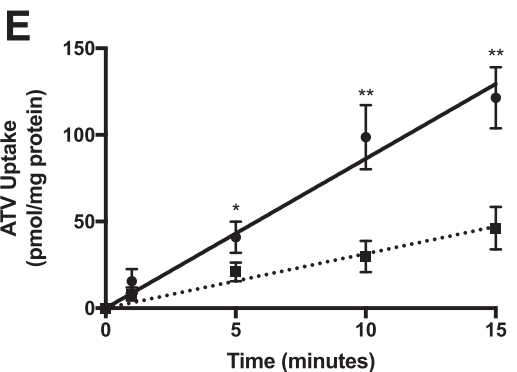

C

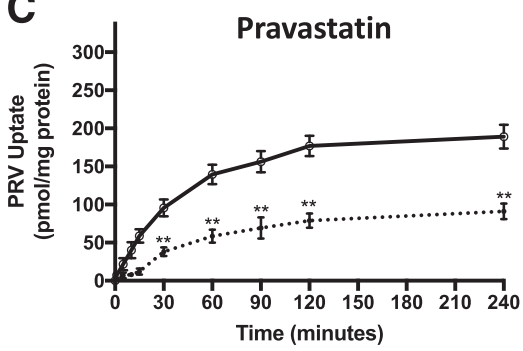

$\mathbf{F}$

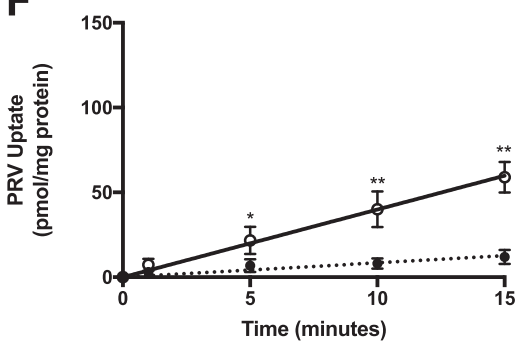

D

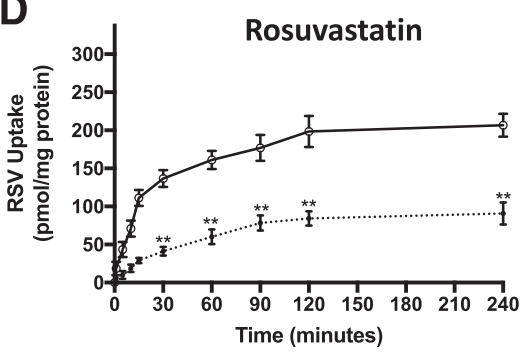

G

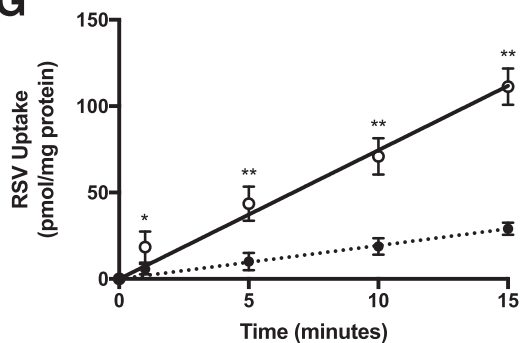

Fig. 1. Expression and transport activity of OATP1A2 in human endothelial cells. (A) OATP1A2 protein expression was detected in HUVECs and in HeLa cells (i.e., positive control) by Western blot analysis. Crude membrane preparations $(10 \mu \mathrm{g})$ were resolved on a $4 \%-12 \%$ SDS-polyacrylamide gel, transferred to a PVDF membrane, and analyzed for expression of OATP1A2. Expression of $\beta$-actin was used as a loading control. Cellular uptake of atorvastatin (ATV) (B), pravastatin (PRV) (C), and rosuvastatin (RSV) (D) was evaluated in HUVECs grown on an impermeable substratum. Statin uptake (10 $\mu M$ total concentration) was measured in the presence and absence of E3S $(50 \mu \mathrm{M})$ at 1, 5, 10, 15, 30, 60, 90, 120, and 240 minutes. The linear phase of the uptake curve for atorvastatin (ATV) (E), pravastatin (PRV) (F), and rosuvastatin (RSV) (G) is plotted in separate graphs to evaluate the rate of uptake for currently marketed statins. Solid lines depict statin uptake in the absence of a pharmacological OATP inhibitor. Dashed lines indicate statin uptake in the presence of an OATP transport inhibitor (i.e., E3S). Data are expressed as means \pm S.D. from three independent experiments, with each data point in an individual experiment representing quadruplicate measurements. Asterisks indicate data points that are statistically significant from control $(* P<0.05 ; * * P<0.01)$. 


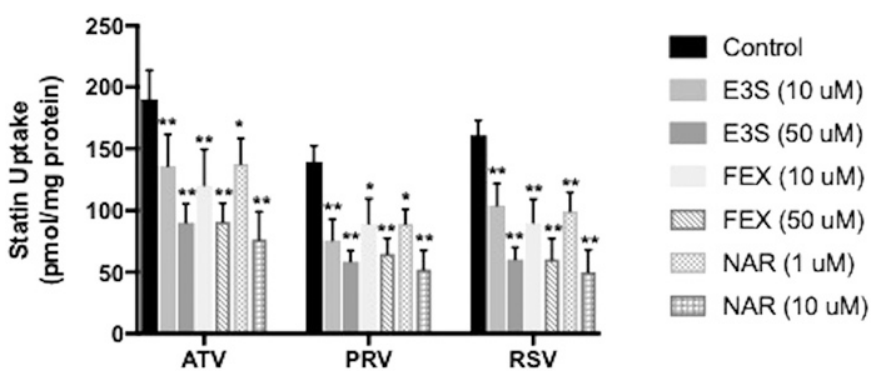

Fig. 2. Effect of OATP transport inhibitors on uptake of statins in human endothelial cells. Cellular accumulation (60 minutes) of atorvastatin (ATV), pravastatin (PRV), and rosuvastatin (RSV) was measured in HUVECs in the presence and absence of E3S $(10,50 \mu \mathrm{M}), \mathrm{FEX}(10$, $50 \mu \mathrm{M})$, and NAR $(1,10 \mu \mathrm{M})$. Data are expressed as means \pm S.D. from three independent experiments, with each data point in an individual experiment representing quadruplicate measurements. Asterisks indicate data points that are statistically significant from control $(* P<0.05 ; * * P<0.01)$.

equivalent to an in vitro concentration of $0.1 \mathrm{nM}$ and that a dose of 1.0 $\mu \mathrm{g} / \mathrm{kg}$ is equivalent to $1 \mathrm{nM}$. These calculations took into account BMP9's molecular mass (i.e., $12.1 \mathrm{kDa}$ ) and the blood volume of a $250 \mathrm{-g}$ Sprague-Dawley rat (i.e., $15.77 \mathrm{ml}$ ) (Ronaldson et al., 2009). LDN193189 is well known to selectively reduce phosphorylation of Smad1/5/8, second messenger proteins involved in signal transduction from the ALK1 receptor (Cuny et al., 2008). In these signaling experiments, the total concentration of DMSO in culture media did not exceed $0.1 \%$. We have shown that $0.1 \%$ DMSO does not affect cellular statin permeability in HUVEC cells at exposure times up to 8 hours (Supplemental Fig. 1). For inhibition experiments, cells were incubated with preincubation buffer containing transport inhibitor for 10 minutes prior to adding transport buffer. At the desired time interval, the radioactive medium was removed, and cells were washed twice with ice-cold HBSS and solubilized in $1 \%$ Triton X-100 at $37^{\circ} \mathrm{C}$ for 30 minutes. The content of each well was collected and mixed with $2.0 \mathrm{ml}$ of Optiphase liquid scintillation cocktail (PerkinElmer), and the total radioactivity was measured with a model 1450 liquid scintillation counter (PerkinElmer). In each experiment, "zero time" uptake (i.e., background) correction was applied to correct for the nonspecific binding and variable quench time, estimated by the retention of radiolabeled compound in the cells after a minimum (zero) time of exposure, determined by removing the radiolabeled buffer immediately after its introduction into the well, followed by two washes with ice-cold HBSS and collection of cells for liquid scintillation counting. Uptake of radiolabeled probes was normalized to total cellular protein content per well, which was measured by using Bradford's method with BSA as the standard.

Drug permeability studies across HUVEC monolayers were performed as described by Kis et al. (2013). Briefly, HUVECs were grown on Transwell membrane inserts at $6 \times 10^{4} \mathrm{cell} / \mathrm{cm}^{2}$ initial seeding density and were allowed to grow for 18-20 days to achieve full differentiation of the confluent monolayer. Prior to initiating permeability studies, the transendothelial electrical resistance across HUVEC monolayers grown in Transwell inserts was measured. Since transendothelial electrical resistance values for HUVEC monolayers on Transwell inserts was $\sim 100 \Omega \mathrm{cm}^{2}$, our permeability experiments required correction for paracellular solute flux using an equimolar concentration of $\left[{ }^{14} \mathrm{C}\right]$ sucrose. Solutions of $\left[{ }^{3} \mathrm{H}\right]$ atorvastatin, $\left[{ }^{3} \mathrm{H}\right]$ pravastatin, or $\left[{ }^{3} \mathrm{H}\right]$ rosuvastatin were prepared in transport buffer and warmed to $37^{\circ} \mathrm{C}$. The radiolabeled drug was administered into the donor chamber (apical or basolateral), and its appearance was measured over 10 minutes in the receiver chamber (basolateral or apical, respectively) by liquid scintillation counting. This approach enabled the estimation of apparent permeability coefficients $\left(\mathrm{P}_{\mathrm{App}}\right)$, which were calculated using eq. 1 : 


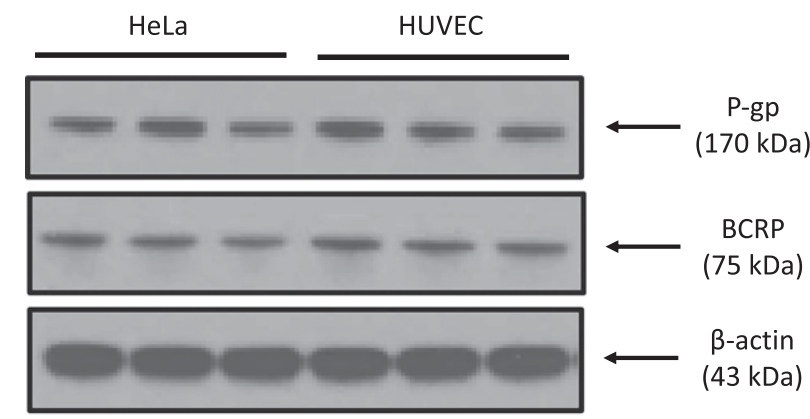

B

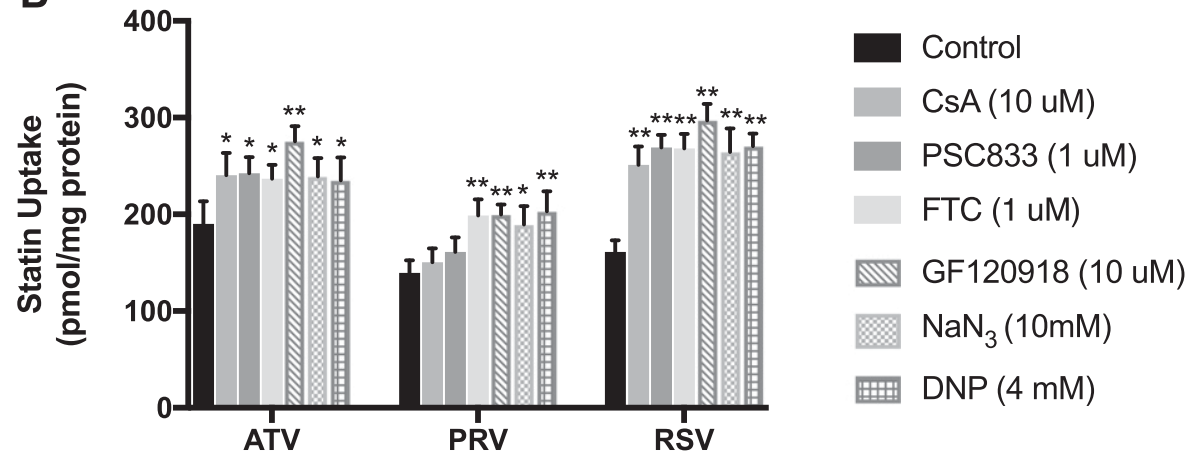

Fig. 3. Effect of efflux transporters on uptake of statins in human endothelial cells. (A) P-gp and BCRP protein expression were detected in HUVECs and in HeLa cells (i.e., positive control) by Western blot analysis. Crude membrane preparations $(10 \mu \mathrm{g})$ were resolved on a $4 \%-12 \%$ SDS-polyacrylamide gel, transferred to a PVDF membrane, and analyzed for expression of P-gp or BCRP. Expression of $\beta$-actin was used as a loading control. (B) Cellular accumulation (60 minutes) of atorvastatin (ATV), pravastatin (PRV), and rosuvastatin (RSV) was measured in HUVECs in the presence and absence of CsA $(10 \mu \mathrm{M})$, PSC833 $(1 \mu \mathrm{M})$, FTC $(1 \mu \mathrm{M})$, GF120918 $(10 \mu \mathrm{M}), \mathrm{NaN}_{3}(10 \mathrm{mM})$, or DNP $(4 \mathrm{mM})$. Data are expressed as means \pm S.D. from three independent experiments, with each data point in an individual experiment representing quadruplicate measurements. Asterisks indicate data points that are statistically significant from control $(* P<0.05 ; * * P<0.01)$.

$$
P_{A p p}=\frac{\Delta Q}{\Delta t} x \frac{1}{A x C_{O}}
$$

where $P_{A p p}$ is the apparent permeability coefficient (centimeters per second), $\Delta Q / \Delta t$ is the rate of solute flux (moles per second) from the donor chamber into the receiver chamber at steady state, $A$ is the surface area of the filter insert (centimeter square), and $C_{O}$ is the initial solute concentration (moles per cubic centimeter) in the donor compartment. $\left[{ }^{3} \mathrm{H}\right]$ Atorvastatin, $\left[{ }^{3} \mathrm{H}\right]$ pravastatin, or $\left[{ }^{3} \mathrm{H}\right]$ rosuvastatin fluxes measured in the apical-to-basolateral and basolateral-to-apical direction were then used to calculate the influx ratio (IR), defined as the quotient of the absorptive (i.e., apical-to-basolateral) permeability and the secretory (i.e., basolateral-to-apical) permeability. IR values were determined according to eq. 2 :

$$
I R=\frac{P_{A p p, A-B}}{P_{A p p, B-A}} .
$$

IRs demonstrate the importance of specific uptake transporters such as OATPs in facilitating (IR $>1$ ) or restricting (IR $<1$ ) drug permeability across an endothelial cellular layer. For inhibition experiments, pharmacological transport inhibitors (i.e., $50 \mu \mathrm{M}$ E3S or $10 \mu \mathrm{M}$ GF120918) were introduced into the apical chamber, and cells were incubated for 20 minutes prior to addition of the radiolabeled drug. To study the role of TGF- $\beta /$ ALK1 signaling on OATPmediated statin permeability in HUVEC cells, BMP-9 (1 nM in $100 \%$ DMSO) was added to either the apical or basolateral chamber 6 hours before administration of radiolabeled statins. To evaluate the specificity of BMP-9 at the ALK1 receptor, LDN193189 $(10 \mu \mathrm{M})$ was introduced to either the apical or basolateral chamber 1 hour before addition of BMP-9 to the same chamber. Similar to uptake experiments, the concentration of DMSO in either the apical or the basolateral chamber did not exceed $1 \%$.

Data Analysis. Each in vitro experiment was repeated at least three times using cells from different passages. In an individual experiment, each data point represents quadruplicate trials. Transport data are presented as means \pm S.D. Statistical analysis was performed using GraphPad Prism (version 7.0c for Mac OS X; Graph Pad Software, San Diego, CA). Statistical significance was analyzed by

applying the unpaired or paired Student's $t$ test for unpaired or paired experimental values or the one-way ANOVA for test of repeated measures, as appropriate. A $P$ value less than 0.05 was considered to be statistically significant.

\section{Results}

Statins are Transported by OATP1A2 in Human Endothelial Cells. We have demonstrated that uptake transport of currently marketed statins in rodent microvascular endothelial cells is mediated by Oatp1a4 (Thompson et al., 2014; Abdullahi et al., 2018; Brzica et al., 2018); however, transport properties of statins by its human ortholog OATP1A2 have not been examined in detail. Therefore, we sought to evaluate OATP1A2 transport properties for statins in HUVECs. Using Western blot analysis, we detected a single band at approximately $60 \mathrm{kDa}$ that corresponds to OATP1A2 protein expression (Fig. 1A). Since statins are also transport substrates for OATP1B1, OATP1B3, and OATP2B1 (Ronaldson and Davis, 2013), we analyzed HUVECs for expression of these specific transporters. Specific bands for OATP1B1, OATP1B3, and OATP2B1 were not detected in HUVECs (Supplemental Fig. 2), which suggests that these transporters are not expressed in this in vitro model.

The time course of atorvastatin, pravastatin, and rosuvastatin cellular uptake at $37^{\circ} \mathrm{C}$ by HUVECs shows increasing accumulation until a steady state is reached at approximately 2 hours (Fig. 1, B-D). Uptake was reduced in the presence of $50 \mu \mathrm{M}$ E3S, a known OATP transport inhibitor. As demonstrated by area under the curve analysis between 0 and 240 minutes, E3S reduced cellular statin exposure by $213.4 \%$ for atorvastatin, $224.5 \%$ for pravastatin, and $244.4 \%$ for rosuvastatin (Table 1 ). The rate of OATP1A2mediated statin uptake can be determined by the slope of the 


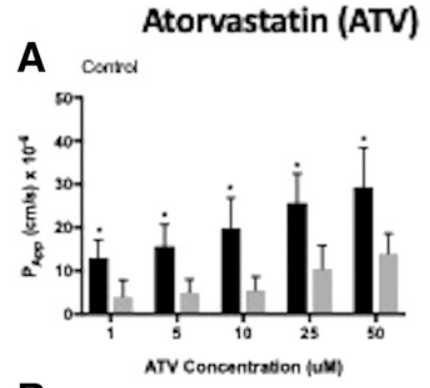

B
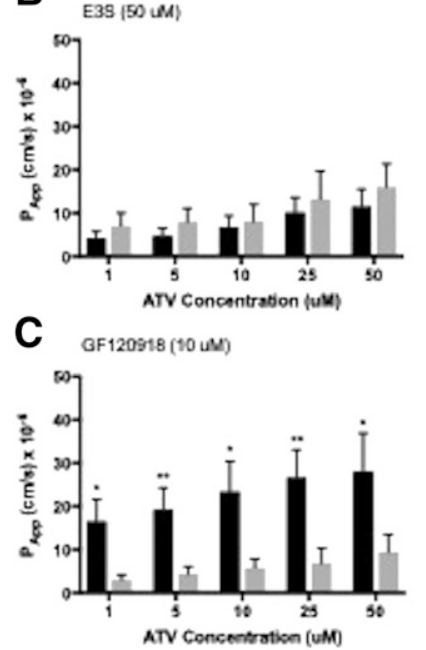
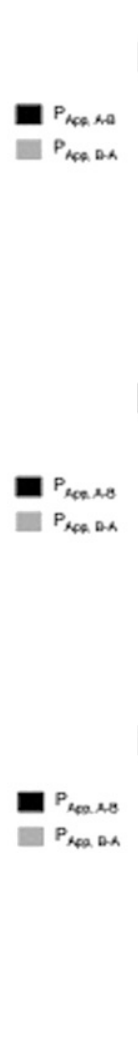

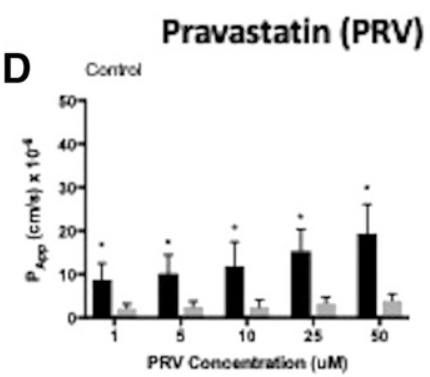

$\mathbf{E}$

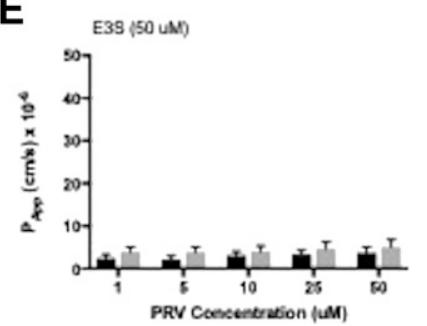

$\mathbf{F}$

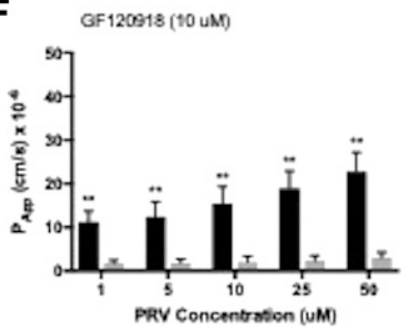

Rosuvastatin (RSV)
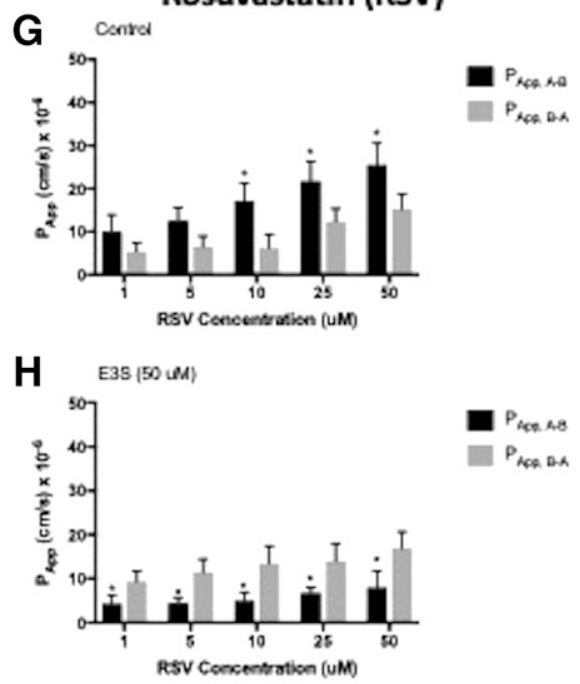

I

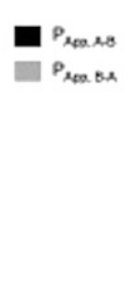

PRV) Cellular monolayer permeability of statins in human endothelial cells. Concentration dependence of atorvastatin (ATV), pravastatin Absorptive and secretory fluxes were determined by introducing a statin drug into the donor compartment and measuring its appearance over time in the receiver compartment. Experiments were conducted in the absence of inhibitor (A, D, and G), in the presence of $50 \mu \mathrm{M}$ E3S (B, E, and $\mathrm{H})$, or in the presence of $10 \mu \mathrm{M}$ GF 120918 (C, F, and I). Data are expressed as means \pm S.D. from three independent experiments, with each data point in an individual experiment representing quadruplicate measurements. Asterisks indicate data points that are statistically significant from control $(* P<0.05 ; * * P<0.01)$.

time course uptake component that displayed linearity, which was detected between time 0 and 15 minutes (Fig. 1, E-G). The rate of OATP1A2-mediated uptake was greatest for atorvastatin, followed by rosuvastatin and then pravastatin. In the presence of $50 \mu \mathrm{M}$ E3S, the rate of uptake was reduced by $274.8 \%$ for atorvastatin, $469.4 \%$ for pravastatin, and $386.0 \%$ for rosuvastatin (Table 1). All transport studies were conducted on HUVECs that were passaged no more than four times. Across this range of passages, we showed that protein expression of OATP1A2 remained consistent (Supplemental Fig. 2).

We also performed inhibition studies in the presence and absence of OATP transport inhibitors (E3S, FEX, NAR) to confirm transport specificity. Cellular uptake of atorvastatin was reduced $(P<0.05)$ in the presence of $10 \mu \mathrm{M} \mathrm{E3S} \mathrm{(1.4-fold),}$ $50 \mu \mathrm{M}$ E3S (2.1-fold), $10 \mu \mathrm{M}$ FEX (1.6-fold), $50 \mu \mathrm{M}$ FEX (2.1fold), $1 \mu \mathrm{M}$ NAR (1.4-fold), and $10 \mu \mathrm{M} \mathrm{NAR} \mathrm{(2.5-fold)} \mathrm{(Fig.} \mathrm{2).}$ Similarly, pravastatin uptake was decreased $(P<0.05)$ up to 2.7 -fold, and cellular uptake of rosuvastatin was reduced $(P<$ 0.05 ) up to 3.2-fold by these same inhibitors. Previous studies have shown that E3S and FEX are substrates and/or inhibitors of multiple OATP isoforms (Ishiguro et al., 2006; Liu et al., 2015; Albekairi et al., 2019). Since we did not detect OATP1B1, OATP1B3, and OATP2B1 in HUVECs (Supplemental Fig. 2), we can attribute effects of E3S and FEX on statin uptake to inhibition of OATP1A2. Additionally, NAR is potent clinical inhibitor of OATP1A2-mediated transport (Bailey et al.,
2007). Therefore, these data provide evidence for OATP1A2mediated transport of statins in human endothelial cells.

P-gp and BCRP Contribute to the Membrane Transport of Currently Marketed Statins. OATPs are not the only membrane transporters involved in determining cellular statin disposition. Many currently marketed statins are substrates for members of the ATP-binding cassette superfamily of efflux transporters such as P-gp and BCRP. Therefore, we sought to measure cellular uptake of atorvastatin, pravastatin, and rosuvastatin in the presence and absence of P-gp inhibitors (i.e., CsA, PSC833), a BCRP inhibitor (i.e., FTC), and a mixed P-gp/BCRP inhibitor (i.e., GF120918). The published $\mathrm{IC}_{50}$ values for $\mathrm{CsA}$, PSC833, and GF120918 versus human P-gp are reported to be in the low micromolar range (Ke et al., 2013; Kosa et al., 2018). Similarly, the reported $\mathrm{IC}_{50}$ values for both FTC and GF120918 against human BCRP are also in the low micromolar range (González-Lobato et al., 2010; Kosa et al., 2018). All concentrations for our efflux transporter experiments were selected to ensure both selectivity for individual transporters and measurable transporter inhibition. Since P-gp and BCRP are ATP-dependent transporters, we also examined statin cellular uptake in the presence and absence of metabolic inhibitors such as $\mathrm{NaN}_{3}$ and DNP. As shown in Fig. 3A, Western blot analysis confirmed the presence of a single band in HUVECs at 170 and at $75 \mathrm{kDa}$, which correspond to P-gp and BCRP, respectively. We did not include multidrug resistance protein 2, a critical statin transporter (Abe et al., 
2008), in our study because we did not detect its protein expression in HUVECs (data not shown). Similar to OATP1A2, we showed that P-gp and BCRP protein expression did not change across four passages of HUVECs (Supplemental Fig. 3). Atorvastatin uptake was increased $(P<0.05)$ in the presence of $10 \mu \mathrm{M}$ CsA, $1 \mu \mathrm{M}$ PSC833, $1 \mu \mathrm{M}$ FTC, $10 \mu \mathrm{M}$ GF120918, $10 \mathrm{mM} \mathrm{NaN}$, or $4 \mathrm{mM} \mathrm{DNP}$ (Fig. 3B). Accumulation of rosuvastatin was also enhanced $(P<0.01)$ by these same inhibitors; however, inhibitors targeting ATP-binding cassette transporters increased rosuvastatin up to 1.8 -fold, whereas atorvastatin was only increased up to 1.4-fold. Uptake of pravastatin was increased $(P<0.05)$ in the presence of OATP, $\mathrm{BCRP}$, or metabolic inhibitors; however, P-gp inhibitors had no effect on cellular uptake of this compound.

Statin Permeability Across HUVEC Monolayers Is Dependent upon OATP1A2 and P-gp/BCRP. To examine the role of transporters in facilitating statin permeability in vascular endothelial cells, we evaluated in vitro flux across HUVEC monolayers grown on Transwell microporous filter membranes. These experiments were conducted in the presence or absence of E3S or GF120918. In the absence of inhibitors, apparent permeability of atorvastatin $(1 \mu \mathrm{M})$ in the apical-to-basolateral direction $\left(\mathrm{P}_{\mathrm{App}, \mathrm{A}-\mathrm{B}}\right)$ was higher $(P<$ 0.05 ) than that measured in the basolateral-to-apical direction ( $\mathrm{P}_{\mathrm{App}, \mathrm{B}-\mathrm{A}}$ ) (Fig. 4A). With increasing atorvastatin concentrations, the atorvastatin IR decreased, implying a saturable transport process (Table 2). Addition of E3S $(50 \mu \mathrm{M})$ resulted in reduced apical-to-basolateral flux (Fig. 4B). In contrast, GF120918 $(10 \mu \mathrm{M})$ treatment caused increased apical-tobasolateral flux (Fig. 4C). Similar effects of E3S or GF120918 on $\mathrm{P}_{\mathrm{App}}$, A-B and $\mathrm{P}_{\mathrm{App}}$, B-A values for pravastatin (Fig. 4, D-F) and rosuvastatin (Fig. 4, G-I) were observed. IRs for both pravastatin and rosuvastatin decreased with increasing concentrations, indicating a saturable membrane transport process for these two compounds (Table 2). Comparison of IRs at $10 \mu \mathrm{M}$ for each statin uncovered some distinct differences in transport properties between atorvastatin, pravastatin, and rosuvastatin (Table 2). The IR under control conditions was highest for pravastatin, which suggests that this compound has a greater dependence on uptake transporters to facilitate its disposition across an endothelial monolayer. The dependence of OATP1A2 on apical-to-basolateral flux of statins is emphasized by the reduction in IRs by E3S, which were all less than 1, suggesting restriction of uptake transport mechanisms. It is critical to point out that the IR for rosuvastatin was 3-fold higher than atorvastatin and 1.6-fold higher than pravastatin in the presence of GF120918 (10 $\mu \mathrm{M})$, which suggests that P-gp and BCRP play a greater role in determining the apical-to-basolateral permeability of rosuvastatin as compared with atorvastatin or pravastatin.

OATP1A2 Expression in HUVECs Is Increased After BMP-9 Treatment. Previously, we showed that BMP-9 treatment increases Oatp1a4 protein expression in rat brain microvasculature (Abdullahi et al., 2017a, 2018). We also demonstrated that this effect involves direct regulation of the solute carrier family gene Slco1a4 by the TGF- $\beta$ /ALK1 pathway (Abdullahi et al., 2018); however, involvement of this pathway in regulation of OATP1A2 has not been demonstrated. Western blot analysis confirmed expression of the ALK1 receptor in HUVECs (Fig. 5A). To show whether BMP-9 can increase OATP1A2 protein expression in HUVECs, we performed a concentration- 


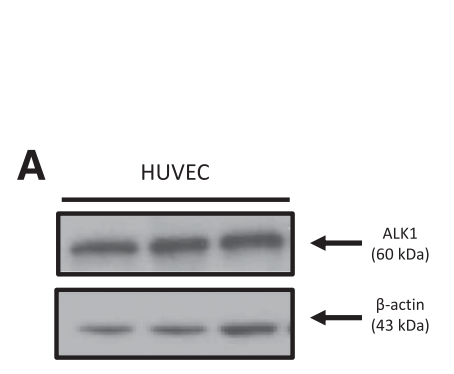

B

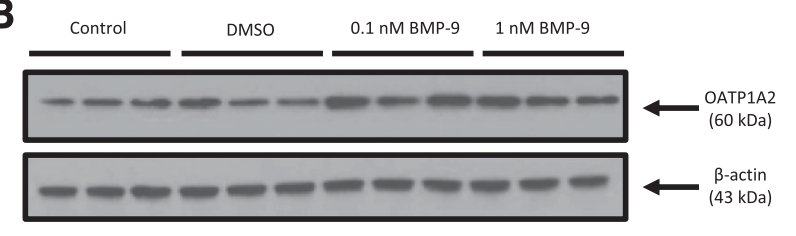

C

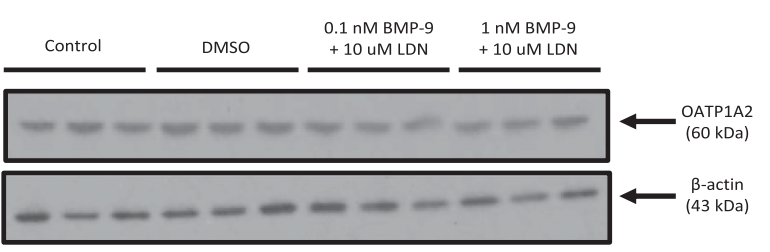

D

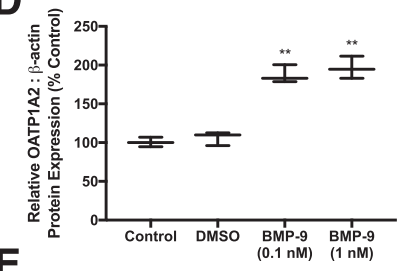

E

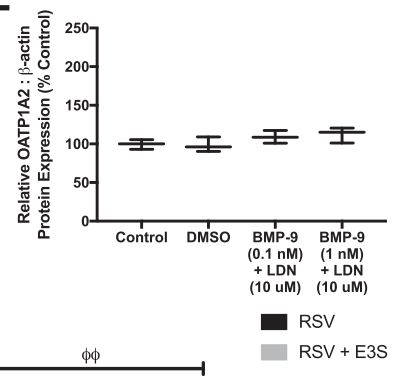

H

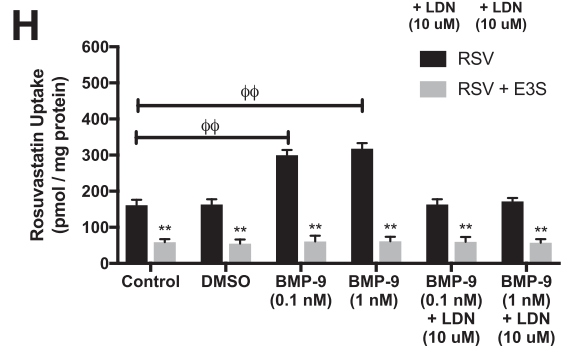

Fig. 5. BMP-9 increases OATP1A2 expression and transport activity in human endothelial cells. (A) ALK1 protein expression was detected in HUVECs by Western blot analysis. Crude membrane preparations $(10 \mu \mathrm{g})$ were resolved on a $4 \%-12 \%$ SDS-polyacrylamide gel, transferred to a PVDF membrane, and analyzed for expression of ALK1. Expression of $\beta$-actin was used as a loading control. (B) HUVECs were treated with 0.1 or $1 \mathrm{nM}$ BMP-9. After 6 hours of incubation at $37^{\circ} \mathrm{C}$ with BMP-9, cells were harvested, and crude membrane samples were prepared. Crude membrane samples $(10 \mu \mathrm{g})$ were resolved on a $4 \%-12 \%$ SDS-polyacrylamide gel, transferred to a PVDF membrane, and analyzed for expression of OATP1A2. (C) Relative levels of OATP1A2 protein expression after BMP-9 treatment were determined by densitometric analysis and normalized to $\beta$-actin. (D) HUVECs were treated with $10 \mu \mathrm{M}$ LDN193189 for 1 hour prior to addition of 0.1 or $1 \mathrm{nM}$ BMP-9. After 6 hours of incubation at $37^{\circ} \mathrm{C}$ with BMP-9, cells were harvested and crude membrane samples were prepared. Crude membrane samples $(10 \mu \mathrm{g})$ were resolved on a 4\%-12\% SDS-polyacrylamide gel, transferred to a PVDF membrane, and analyzed for expression of OATP1A2. (E) Relative levels of OATP1A2 protein expression after LDN193189/BMP-9 treatment were determined by densitometric analysis and normalized to $\beta$-actin. Cellular accumulation (60 minutes) of atorvastatin $(\mathrm{F})$, pravastatin $(\mathrm{G})$, and rosuvastatin $(\mathrm{H})$ was measured in HUVECs in the presence and absence of E3S $(50 \mu \mathrm{M})$. Western blot densitometric data are reported as means \pm S.D. from three independent experiments. Transport assay data are expressed as means \pm S.D. from three independent experiments, with each data point in an individual experiment representing quadruplicate measurements. Asterisks indicate data points that are statistically significant from control $\left(* P<0.05 ; * * P<0.01 ; \phi \phi P<0.01\right.$ comparing $\mathrm{P}_{\mathrm{App}}$, A-B between control and BMP-9-treated cells).

response experiment. Cells were treated with 0.1 or $1 \mathrm{nM}$ BMP-9 for 6 hours, and then HUVECs were evaluated for OATP1A2 protein expression. In the presence of 0.1 or $1 \mathrm{nM}$ BMP-9, OATP1A2 protein expression was increased up to 2.0 -fold (Fig. 5, $\mathrm{B}$ and $\mathrm{C}$ ). No change in OATP1A2 protein expression was observed in cells treated with vehicle (i.e., 0.1\% DMSO). To confirm that the BMP-9 effect on OATP1A2 expression was mediated by TGF- $\beta$ /ALK1 signaling, we used LDN193189, a pharmacological ALK1 receptor antagonist. Administration of LDN193189 $(10 \mu \mathrm{M}) 1$ hour prior to BMP-9 treatment attenuated the increase in OATP1A2 protein expression that was induced by either 0.1 or $1 \mathrm{nM}$ BMP-9 (Fig. 5, D and E).

To determine whether increased OATP1A2 protein expression after BMP-9 treatment correlates with enhanced OATP-mediated statin transport, we measured cellular accumulation of atorvastatin, pravastatin, or rosuvastatin after treatment with BMP-9 or with LDN193189 and BMP-9. OATP transport specificity was confirmed by conducting all of these experiments in the presence and absence of E3S $(50 \mu \mathrm{M})$. Cellular uptake of atorvastatin was enhanced 2.0-fold after 0.1 nM BMP-9 treatment and 2.1-fold after $1 \mathrm{nM}$ BMP-9 treatment (Fig. 5F). Similarly, accumulation of pravastatin was increased 2.1-fold after $0.1 \mathrm{nM}$ BMP-9 treatment and 2.2-fold after $1 \mathrm{nM}$ BMP-9 treatment (Fig. 5G). Congruent observations were observed with rosuvastatin in which 0.1 and $1 \mathrm{nM}$
BMP-9 enhanced cellular uptake by 1.9 -fold and 2.0-fold, respectively (Fig. 5H). Pretreatment with LDN193189 attenuated these increases in cellular statin accumulation for all three compounds tested. Additionally, E3S reduced uptake into HUVECs for atorvastatin, pravastatin, and rosuvastatin across all treatment conditions, thereby confirming involvement of an OATP-mediated transport mechanism.

Apical Plasma Membrane Exposure to BMP-9 Increases Statin Uptake Transport in HUVECs. Since HUVECs are polarized cells, we wanted to determine whether BMP-9 could modulate OATP-mediated statin transport when directly applied to the apical or to the basolateral plasma membrane. In the first series of these experiments, BMP-9 (1 nM) was added to the apical Transwell compartment, and cells were incubated for 6 hours at $37^{\circ} \mathrm{C}$ (Fig. 6A). These conditions resulted in a 1.9-fold increase in $\mathrm{P}_{\mathrm{App}, \mathrm{A}-\mathrm{B}}$ for atorvastatin (Fig. 6B). Similarly, the $\mathrm{P}_{\mathrm{App}, \mathrm{A}-\mathrm{B}}$ for pravastatin was enhanced by 2.2 -fold (Fig. 6C), and the $\mathrm{P}_{\mathrm{App}}$, A-B for rosuvastatin was increased by 1.8-fold (Fig. 6D) after BMP-9 treatment. Of particular importance, HUVEC exposure to BMP-9 did not result in any statistically significant change to $\mathrm{P}_{\mathrm{App}}$, B-A for any statin tested. Application of BMP-9 to the apical plasma membrane of HUVECs increased IRs for atorvastatin, pravastatin, and rosuvastatin (Table 3). To confirm involvement of TGF- $\beta$ /ALK1 signaling in this response, we performed 
A
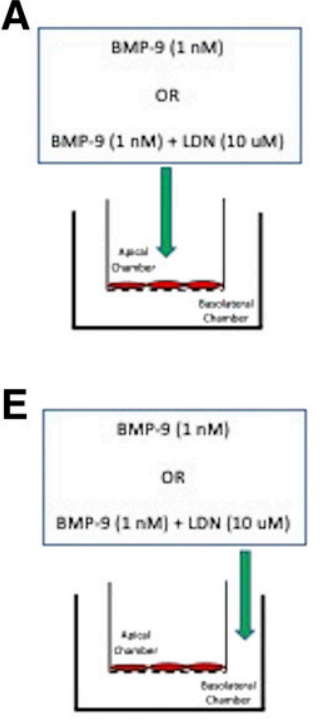

B

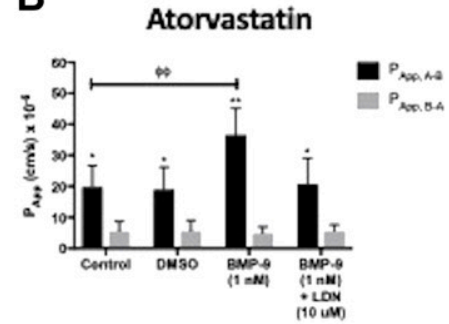

F

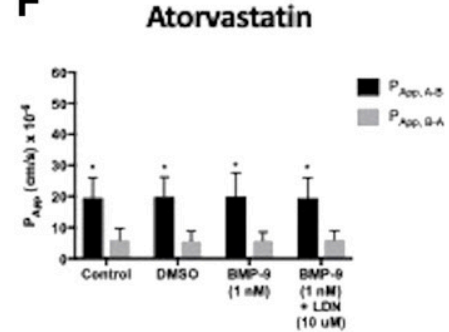

C

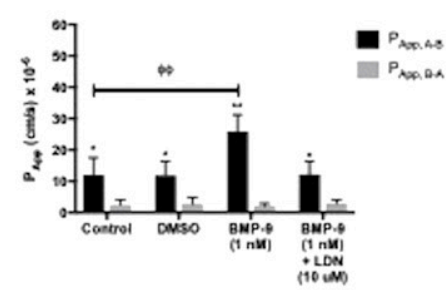

G

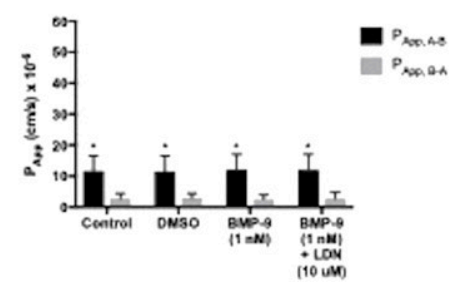

D

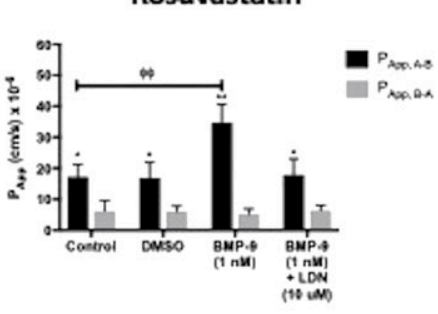

H

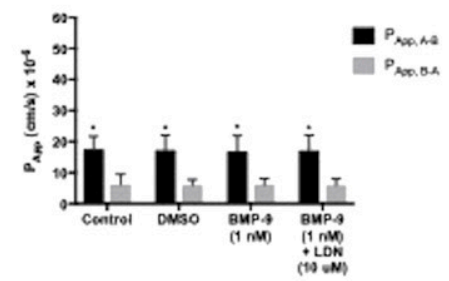

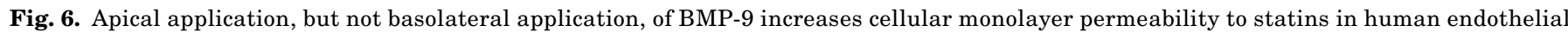

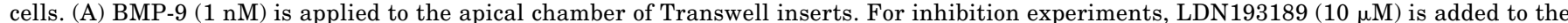

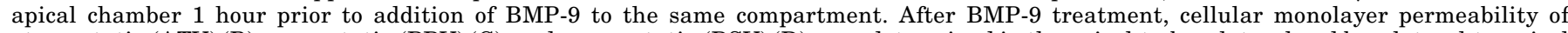

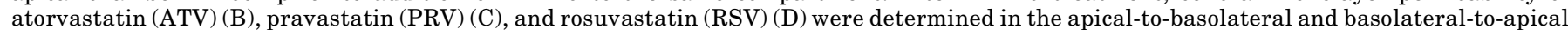

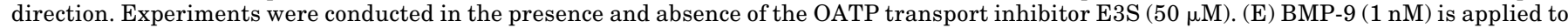

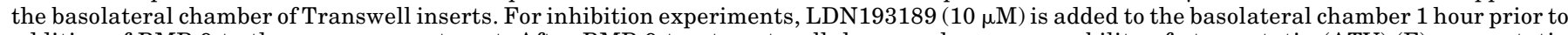

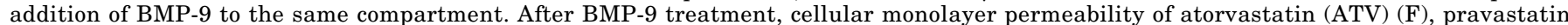

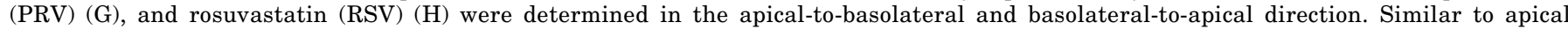

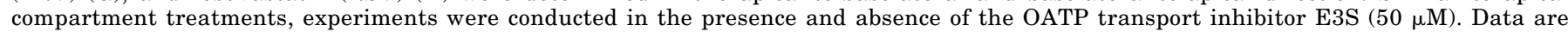

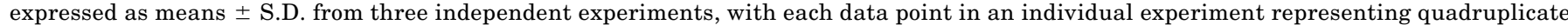

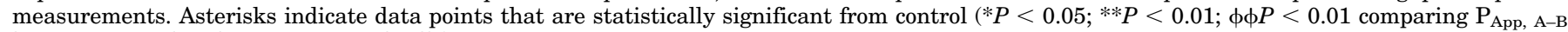
between control and BMP-9-treated cells).

additional experimentation in which LDN193189 $(10 \mu \mathrm{M})$ was added to the apical compartment 1 hour prior to BMP-9 administration. In these studies, pretreatment with LDN193189 attenuated the BMP-9-stimulated increases in $\mathrm{P}_{\mathrm{App}, \mathrm{A}-\mathrm{B}}$ and the IR for all three statins (Table 3).

The second set of these experiments involved addition of BMP-9 to the basolateral chamber, followed by incubation of HUVECs for 6 hours at $37^{\circ} \mathrm{C}$ (Fig. $6 \mathrm{E}$ ). Under these conditions, BMP-9 did not induce any significant change in $\mathrm{P}_{\mathrm{App}}$, A-B for atorvastatin (Fig. 6F), pravastatin (Fig. 6G), or rosuvastatin (Fig. 6H). Similar to data obtained after apical BMP-9 exposure, there was no effect on $\mathrm{P}_{\mathrm{App}, \mathrm{B}-\mathrm{A}}$ for any of the statins examined in this study. Basolateral BMP-9 experiments were also performed in the presence of LDN193189. When HUVECs were treated with both LDN193189 and BMP-9, no effect on either $\mathrm{P}_{\mathrm{App}}$, A-B or $\mathrm{P}_{\mathrm{App}}$, B-A was detected for atorvastatin, pravastatin, or rosuvastatin. As shown in Table 4, administration of BMP-9 or LDN193189/BMP-9 to the basolateral chamber had no effect on the IR for either atorvastatin, pravastatin, or rosuvastatin. Taken together, these data provide evidence for regulation of OATP1A2-mediated statin transport by an apical plasma membrane signaling mechanism that involves the TGF- $\beta$ /ALK1 pathway.

\section{Discussion}

Our laboratory is focused on studying BBB transporters that can be exploited for CNS delivery of drugs. Our current work is focused on statins, which exhibit neuroprotective properties independent of their effects on circulating cholesterol (Zhang et al., 2009; Fang et al., 2015). Statins show clinical translation as evidenced by improved poststroke recovery (Montaner et al., 2016; Lee et al., 2017; Malhotra et al., 2019). Another difference between statins and other compounds believed to be effective in stroke is that statins are known substrates for an endogenous BBB transporter (i.e., OATP1A2). Immunohistochemical studies have localized OATP1A2 to human brain endothelial cells (Bronger et al., 2005; Lee et al., 2005). These observations are supported by various proteomic approaches that have shown quantifiable OATP1A2 expression in frontal cortex microvessels (AlMajdoub et al., 2019). In contrast, quantitative targeted proteomics has failed to detect OATP1A2 at the BBB in Brodmann areas 17 and 39 (Billington et al., 2019). These studies imply that regional differences in $\mathrm{BBB}$ expression of OATP1A2 may exist; however, such results must be confirmed by detailed molecular studies and functional analyses. Of significance to our work, Al-Majdoub et al. (2019) showed that relative abundance of OATP1A2 in frontal cortex microvessels was greater than that of OATP1B3, OATP1C1, or OATP2B1. Indeed, ischemic injury to the frontal cortex results in cognitive and motor impairment. Therefore, delivery of statins via OATP1A2-mediated transport is a strategy that can improve stroke pharmacotherapy.

Statin transport properties by OATP1A2 can be evaluated using HUVECs. Nontransfected cell culture systems have advantages over genetically modified in vitro models or CRISPR/Cas9 modified "knock-in" animals. Firstly, OATP1A2 expression in nontransfected cells is more representative of endogenous transporter expression, thereby providing a more physiologically relevant model to study statin transport properties. Secondly, transfected cell culture systems are 
subject to compensatory changes by other transporters, an effect that can greatly confound cellular uptake and/or monolayer permeability data. Evaluation of OATP1A2-mediated statin transport requires the consideration that statins are substrates for multiple human OATP family members, including OATP1A2, OATP1B1, OATP1B3, and OATP2B1 (Ronaldson and Davis, 2013). Of these transporters, only OATP1A2 was detectable in HUVECs, which confirms the utility of these cells for evaluation of OATP1A2-mediated transport properties. Other OATP isoforms (i.e., OATP1C1, OATP2A1) may also be expressed in human endothelial cells. Although these transporters are believed to have a more limited substrate profile as compared with OATP1A2 (van der Deure et al., 2008; Kasai et al., 2016), future studies must evaluate the potential of OATP1C1 and OATP2A1 to transport statins in endothelial cells.

In this study, we examined three statins that differ in physicochemical properties and efflux transport liability. Atorvastatin is a hydrophobic statin that is a substrate for P-gp and BCRP (Hochman et al., 2004; Li et al., 2011). Rosuvastatin is a hydrophilic drug and P-gp/BCRP substrate (Li et al., 2011; Safar et al., 2019). Pravastatin is a hydrophilic statin and a transport substrate for BCRP (Hirano et al., 2005) but does not have measurable P-gp affinity (Bogman et al., 2001). Indeed, expression of P-gp in HUVECs is controversial. Although some studies have reported lack of P-gp expression in this in vitro model (Dauchy et al., 2009; Ohtsuki et al., 2013), others have confirmed functional expression of P-gp in HUVECs (Dombrowski et al., 2001; Krawczenko et al., 2017). In contrast, there is greater consensus on BCRP expression in HUVECs, which has been demonstrated at both the mRNA and protein level (Dauchy et al., 2009; Ohtsuki et al., 2013; Komori et al., 2018). In our hands, we observed protein expression of both P-gp and BCRP in HUVECs. To evaluate the role of OATP1A2, P-gp, and BCRP on statin transport in HUVECs, we examined effects of pharmacological inhibitors on 1) in vitro uptake of atorvastatin, pravastatin, and rosuvastatin and 2) absorptive (i.e., apical-to-basolateral) and secretory (i.e., basolateral-to-apical) flux of these statins across monolayers grown on Transwell membrane inserts. Accumulation of atorvastatin and rosuvastatin were highly susceptible to inhibition by OATP inhibitors (i.e., E3S, FEX, NAR), P-gp inhibitors (i.e., CsA, PSC833), a BCRP inhibitor (i.e., FTC), a "mixed" P-gp/BCRP inhibitor (i.e., GF120918), and metabolic inhibitors that deplete intracellular ATP concentrations (i.e., $\mathrm{NaN}_{3}$, DNP). In contrast, cellular uptake of pravastatin was susceptible to inhibition by all inhibitors except for CsA and PSC833, suggesting that this statin is not a P-gp transport substrate. Our results emphasize the fact that efflux transporters had the greatest effect on rosuvastatin as compared with atorvastatin and pravastatin. Additionally, these results suggest a role for BCRP in limiting uptake and cellular monolayer permeability of pravastatin, whereas efflux transporters have little effect on the apical-to-basolateral permeability of atorvastatin. This was an interesting finding in light of the fact that atorvastatin is a known P-gp and BCRP substrate (Hochman et al., 2004; Li et al., 2011) and likely reflects high in vitro passive permeability of atorvastatin relative to either pravastatin or rosuvastastin (Fredlund et al., 2017).

Our group is the first to demonstrate that signaling via the ALK1 receptor can regulate Oatp1a4 (Abdullahi et al., 2018).

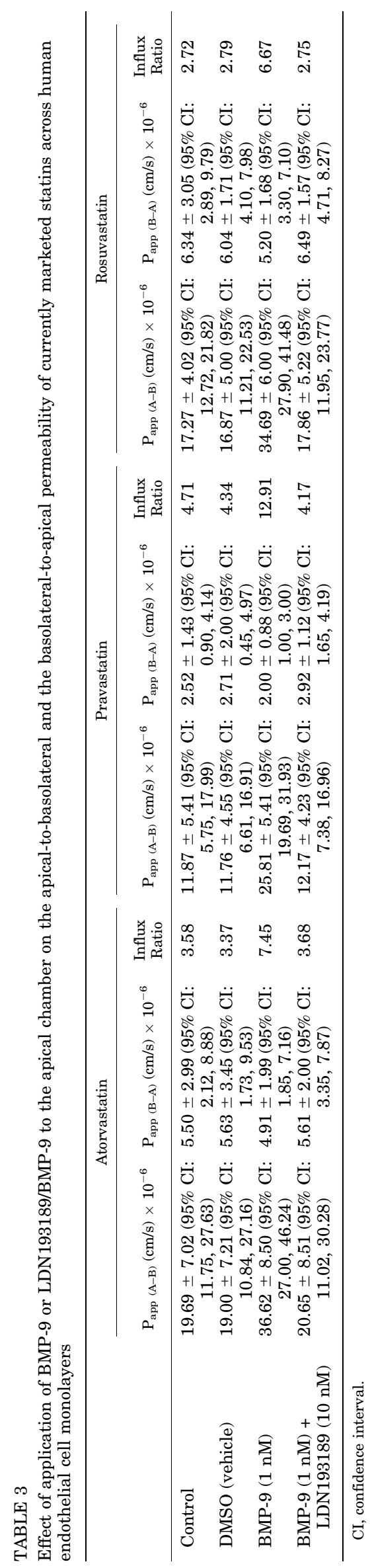




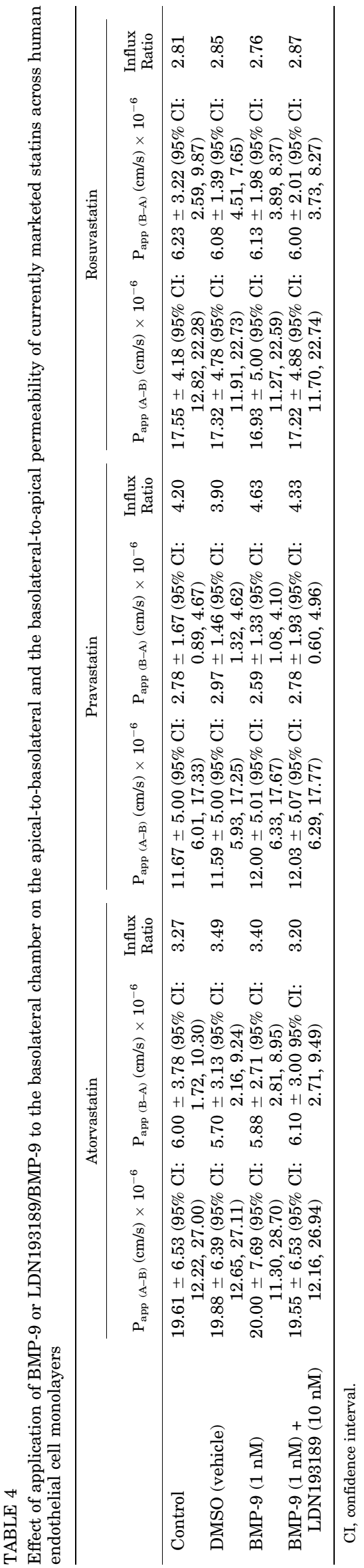

This effect was demonstrated using BMP-9, an endogenous cytokine that is produced by the liver to yield systemic concentrations of $2-12 \mathrm{ng} / \mathrm{ml}$ (David et al., 2008). It is a potent activator of the ALK1 receptor, with an $\mathrm{EC}_{50}$ of $50 \mathrm{pg} / \mathrm{ml}$ (David et al., 2008). In our recent work, we demonstrated that pharmacological doses of BMP-9 (i.e., 0.1 and $1.0 \mu \mathrm{g} / \mathrm{kg}$ ) could induce Oatp1a4 protein expression in rat brain microvessels at 6 hours postinjection (Abdullahi et al., 2017a). In the present study, we showed that comparable BMP-9 concentrations increased OATP1A2 functional expression in vitro. Specificity for the TGF- $\beta$ /ALK1 pathway was established using the pharmacological ALK1 inhibitor LDN193189, which attenuated changes in OATP1A2 protein expression or transport activity induced by BMP-9. Induction of OATP1A2 at 6 hours post-BMP-9 treatment is consistent with our previous work (Abdullahi et al., 2018) and with the temporal relationship between activation of intracellular signaling and de novo synthesis of other transporters known to be expressed in endothelial cells (Miller and Cannon, 2014). It is noteworthy to emphasize that BMP-9 had the greatest effect on the IR for pravastatin ( $274 \%$ increase) and rosuvastatin (245\% increase) as compared with atorvastatin (208\% increase). Indeed, pravastatin and rosuvastatin are more hydrophilic than atorvastatin. which implies that pravastatin and rosuvastatin are more dependent upon OATP1A2-mediated transport to permeate endothelial cells. Similar observations were made by Higgins et al. (2014), who showed that genetic deletion of OATP isoforms in male Friend leukemia virus mice resulted in a greater magnitude of effect on pharmacokinetic properties of hydrophilic statins as compared with hydrophobic statins. Additionally, our data indicate a spatial dependence in which apical plasma membrane BMP-9 exposure results in altered OATP1A2 functional expression, but basolateral BMP-9 application has no effect. This observation is of particular relevance for CNS drug delivery in which OATP1A2 expression and/or activity can be modulated when ligand is administered via the systemic circulation and interacts with ALK1 receptors at the apical plasma membrane of endothelial cells. These results are also consistent with the known apical plasma membrane localization of ALK1 in endothelial cells (Kraehling et al., 2016). Taken together, these data suggest that OATP1A2-mediated statin uptake and permeability in human endothelial cells are regulated via ALK1, a receptor that can be targeted for novel strategies to control drug delivery.

As noted by Liu et al. 2015, differences in transport between OATP1A2 and Oatp1a4 "demonstrate that the rodent is not a good model to investigate the active brain uptake of potential OATP1A2 substrates." We respectfully feel that this statement requires clarification. The Liu study convincingly shows OATP1A2-mediated transport of zolmitriptan but lack of transport of multiple other triptan drugs by Oatp1a4 (Liu et al., 2015). We agree that rodents are not useful in studying transport properties of these antimigraine medications; however, this is not the case for all OATP/Oatp substrate drugs. Examples of common drug substrates of Oatp1a4 and OATP1A2 include opioid analgesic peptides (Ronaldson et al., 2011; Albekairi et al., 2019) and FEX (Kullak-Ublick et al., 2016; Takano et al., 2018). Clearly, translational potential of rodent models to humans requires the evaluation of both OATP1A2 and Oatp1a4 transport properties. We have accomplished this objective for statins via our detailed kinetic studies. We also demonstrate, for the first time, that OATP1A2 
functional expression can be controlled by targeting ALK1 receptors. These current data on OATP1A2 prove the translational potential of our in vivo rodent studies that have shown Oatp1a4-mediated transport of statins (Thompson et al., 2014; Abdullahi et al., 2018; Brzica et al., 2018). Furthermore, our work emphasizes the essential need to consider endothelial transport kinetics during preclinical drug development. By considering apical-to-basolateral permeability mediated by transporters such as OATP1A2, new drugs that are both effective at specific molecular targets and capable of reaching those targets can be accurately identified. This forwardthinking approach may uncover novel compounds that are more likely to have a clinical impact in diseases in which drug development has been difficult, such as ischemic stroke.

\section{Authorship Contributions}

Participated in research design: Ronaldson, Davis.

Conducted experiments: Ronaldson, Brzica, Abdullahi, Reilly.

Performed data analysis: Ronaldson, Brzica, Abdullahi, Reilly.

Wrote or contributed to the writing of the manuscript: Ronaldson, Davis.

\section{References}

Abdullahi W, Brzica H, Hirsch NA, Reilly BG, and Ronaldson PT (2018) Functional expression of organic anion transporting polypeptide 1a4 is regulated by transforming growth factor- $\beta$ /activin receptor-like kinase 1 signaling at the blood-brain barrier. Mol Pharmacol 94:1321-1333.

Abdullahi W, Brzica H, Ibbotson K, Davis TP, and Ronaldson PT (2017a) Bone morphogenetic protein-9 increases the functional expression of organic anion transporting polypeptide $1 \mathrm{a} 4$ at the blood-brain barrier via the activin receptor-like kinase-1 receptor. J Cereb Blood Flow Metab 37:2340-2345.

Abdullahi W, Davis TP, and Ronaldson PT (2017b) Functional expression of P-glycoprotein and organic anion transporting polypeptides at the blood-brain barrier: understanding transport mechanisms for improved CNS drug delivery? AAPS J 19:931-939.

Abe K, Bridges AS, Yue W, and Brouwer KL (2008) In vitro biliary clearance of angiotensin II receptor blockers and 3-hydroxy-3-methylglutaryl-coenzyme A reductase inhibitors in sandwich-cultured rat hepatocytes: comparison with in vivo biliary clearance. J Pharmacol Exp Ther 326:983-990.

Akanuma S, Hirose S, Tachikawa M, and Hosoya K (2013) Localization of organic anion transporting polypeptide (Oatp) $1 \mathrm{a} 4$ and Oatp1c1 at the rat blood-retinal barrier. Fluids Barriers CNS 10:29.

Albekairi TH, Vaidya B, Patel R, Nozohouri S, Villalba H, Zhang Y, Lee YS, AlAhmad A, and Abbruscato TJ (2019) Brain delivery of a potent opioid receptor agonist, biphalin during ischemic stroke: role of organic anion transporting polypeptide (OATP). Pharmaceutics 11:467.

Al-Majdoub ZM, Al Feteisi H, Achour B, Warwood S, Neuhoff S, Rostami-Hodjegan A, and Barber J (2019) Proteomic quantification of human blood-brain barrier SLC and $\mathrm{ABC}$ transporters in healthy individuals and dementia patients. Mol Pharm 16:1220-1233.

Bailey DG, Dresser GK, Leake BF, and Kim RB (2007) Naringin is a major and selective clinical inhibitor of organic anion-transporting polypeptide 1A2 (OATP1A2) in grapefruit juice. Clin Pharmacol Ther 81:495-502.

Billington S, Salphati L, Hop CECA, Chu X, Evers R, Burdette D, Rowbottom C, Lai Y, Xiao G, Humphreys WG, et al. (2019) Interindividual and regional variability in drug transporter abundance at the human blood-brain barrier measured by quantitiative targeted proteomics. Clin Pharmacol Ther 106:228-237.

Bogman K, Peyer AK, Török M, Küsters E, and Drewe J (2001) HMG-CoA reductase inhibitors and P-glycoprotein modulation. Br J Pharmacol 132:1183-1192.

Bronger H, König J, Kopplow K, Steiner HH, Ahmadi R, Herold-Mende C, Keppler D, and Nies AT (2005) ABCC drug efflux pumps and organic anion uptake transporters in human gliomas and the blood-tumor barrier. Cancer Res 65 $11419-11428$.

Brzica H, Abdullahi W, Reilly BG, and Ronaldson PT (2018) Sex-specific differences in organic anion transporting polypeptide 1a4 (Oatp1a4) functional expression at the blood-brain barrier in Sprague-Dawley rats. Fluids Barriers CNS 15:25.

Cuny GD, Yu PB, Laha JK, Xing X, Liu JF, Lai CS, Deng DY, Sachidanandan C, Bloch KD, and Peterson RT (2008) Structure-activity relationship study of bone morphogenetic protein (BMP) signaling inhibitors. Bioorg Med Chem Lett 18 $4388-4392$

Dauchy S, Miller F, Couraud PO, Weaver RJ, Weksler B, Romero IA, Scherrmann JM, De Waziers I, and Declèves X (2009) Expression and transcriptional regulation of ABC transporters and cytochromes P450 in hCMEC/D3 human cerebral microvascular endothelial cells. Biochem Pharmacol 77:897-909.

David L, Mallet C, Keramidas M, Lamandé N, Gasc JM, Dupuis-Girod S, Plauchu H, Feige JJ, and Bailly S (2008) Bone morphogenetic protein-9 is a circulating vascular quiescence factor. Circ Res 102:914-922.

Dombrowski SM, Desai SY, Marroni M, Cucullo L, Goodrich K, Bingaman W, Mayberg MR, Bengez L, and Janigro D (2001) Overexpression of multiple drug resistance genes in endothelial cells from patients with refractory epilepsy. Epilepsia 42:1501-1506.
Fang X, Tao D, Shen J, Wang Y, Dong X, and Ji X (2015) Neuroprotective effects and dynamic expressions of MMP9 and TIMP1 associated with atorvastatin pretreatment in ischemia-reperfusion rats. Neurosci Lett 603:60-65.

Fredlund L, Winiwarter S, and Hilgendorf C (2017) In vitro intrinsic permeability: a transporter-independent measure of Caco-2 cell permeability in drug design and development. Mol Pharm 14:1601-1609.

González-Lobato L, Real R, Prieto JG, Alvarez AI, and Merino G (2010) Differential inhibition of murine Bcrp1/Abcg2 and human BCRP/ABCG2 by the mycotoxin fumitremorgin C. Eur J Pharmacol 644:41-48.

Harati R, Benech H, Villégier AS, and Mabondzo A (2013) P-glycoprotein, breast cancer resistance protein, Organic Anion Transporter 3, and Transporting Peptide 1a4 during blood-brain barrier maturation: involvement of Wnt/ $\beta$-catenin and endothelin-1 signaling. Mol Pharm 10:1566-1580.

Higgins JW, Bao JQ, Ke AB, Manro JR, Fallon JK, Smith PC, and Zamek-Gliszczynski MJ (2014) Utility of Oatp1a/1b-knockout and OATP1B1/3-humanized mice in the study of OATP-mediated pharmacokinetics and tissue distribution: case studies with pravastatin, atorvastatin, simvastatin, and carboxydichlorofluorescein. Drug Metab Dispos 42:182-192.

Hirano M, Maeda K, Matsushima S, Nozaki Y, Kusuhara H, and Sugiyama Y (2005) Involvement of BCRP (ABCG2) in the biliary excretion of pitavastatin. Mol Pharmacol 68:800-807.

Ho RH, Tirona RG, Leake BF, Glaeser H, Lee W, Lemke CJ, Wang Y, and Kim RB (2006) Drug and bile acid transporters in rosuvastatin hepatic uptake: function, expression, and pharmacogenetics. Gastroenterology 130:1793-1806.

Hochman JH, Pudvah N, Qiu J, Yamazaki M, Tang C, Lin JH, and Prueksaritanont T (2004) Interactions of human P-glycoprotein with simvastatin, simvastatin acid, and atorvastatin. Pharm Res 21:1686-1691.

Ishiguro N, Maeda K, Kishimoto W, Saito A, Harada A, Ebner T, Roth W, Igarashi T, and Sugiyama Y (2006) Predominant contribution of OATP1B3 to the hepatic uptake of telmisartan, an angiotensin II receptor antagonist, in humans. Drug Metab Dispos 34:1109-1115.

Ishikawa H, Wakisaka Y, Matsuo R, Makihara N, Hata J, Kuroda J, Ago T, Kitayama J, Nakane H, Kamouchi M, et al.; Fukuoka Stroke Registry Investigators (2016) Influence of statin pretreatment on initial neurological severity and short-term functional outcome in acute ischemic stroke patients: the fukuoka stroke registry. Cerebrovasc Dis 42:395-403.

Kasai T, Nakanishi T, Ohno Y, Shimada H, Nakamura Y, Arakawa H, and Tamai I (2016) Role of OATP2A1 in PGE(2) secretion from human colorectal cancer cells via exocytosis in response to oxidative stress. Exp Cell Res 341:123-131.

Ke AB, Eyal S, Chung FS, Link JM, Mankoff DA, Muzi M, and Unadkat JD (2013) Modeling cyclosporine A inhibition of the distribution of a P-glycoprotein PET ligand, 11C-verapamil, into the maternal brain and fetal liver of the pregnant nonhuman primate: impact of tissue blood flow and site of inhibition. $J$ Nucl Med 54:437-446.

Kis O, Zastre JA, Hoque MT, Walmsley SL, and Bendayan R (2013) Role of drug efflux and uptake transporters in atazanavir intestinal permeability and drug drug interactions. Pharm Res 30:1050-1064.

Komori H, Yamada K, and Tamai I (2018) Hyperuricemia enhances intracellular urate accumulation via down-regulation of cell-surface BCRP/ABCG2 expression in vascular endothelial cells. Biochim Biophys Acta Biomembr 1860:973-980.

Kosa RE, Lazzaro S, Bi YA, Tierney B, Gates D, Modi S, Costales C, Rodrigues AD, Tremaine LM, and Varma MV (2018) Simultaneous assessment of transportermediated drug-drug interactions using a probe drug cocktail in cynomolgus monkey. Drug Metab Dispos 46:1179-1189.

Kraehling JR, Chidlow JH, Rajagopal C, Sugiyama MG, Fowler JW, Lee MY, Zhang X, Ramírez CM, Park EJ, Tao B, et al. (2016) Genome-wide RNAi screen reveals ALK1 mediates LDL uptake and transcytosis in endothelial cells. Nat Commun 7: 13516

Krawczenko A, Bielawska-Pohl A, Wojtowicz K, Jura R, Paprocka M, Wojdat E, Kozłowska U, Klimczak A, Grillon C, Kieda C, et al. (2017) Expression and activity of multidrug resistance proteins in mature endothelial cells and their precursors: a challenging correlation. PLoS One 12:e0172371.

Kullak-Ublick GA, Gubler C, Spanaus K, Ismair MG, Claro da Silva T, and Jetter A (2016) No major effects of vitamin D3 (1,25 dihydroxyvitamin D3) on absorption and pharmacokinetics of folic acid and fexofenadine in healthy volunteers. Eur $J$ Clin Pharmacol 72:797-805.

Lau YY, Huang Y, Frassetto L, and Benet LZ (2007) Effect of OATP1B transporter inhibition on the pharmacokinetics of atorvastatin in healthy volunteers. Clin Pharmacol Ther 81:194-204.

Lee M, Saver JL, Wu YL, Tang SC, Lee JD, Rao NM, Wang HH, Jeng JS, Lee TH, Chen PC, et al. (2017) Utilization of statins beyond the initial period after stroke and 1-year risk of recurrent stroke. J Am Heart Assoc 6:e005658.

Lee W, Glaeser H, Smith LH, Roberts RL, Moeckel GW, Gervasini G, Leake BF, and Kim RB (2005) Polymorphisms in human organic anion-transporting polypeptide 1A2 (OATP1A2): implications for altered drug disposition and centra nervous system drug entry. J Biol Chem 280:9610-9617.

Li J, Volpe DA, Wang Y, Zhang W, Bode C, Owen A, and Hidalgo IJ (2011) Use of transporter knockdown Caco-2 cells to investigate the in vitro efflux of statin drugs. Drug Metab Dispos 39:1196-1202.

Liu H, Yu N, Lu S, Ito S, Zhang X, Prasad B, He E, Lu X, Li Y, Wang F, et al. (2015) Solute carrier family of the organic anion-transporting polypeptides $1 \mathrm{~A} 2$ - madindarby canine kidney II: a promising in vitro system to understand the role of organic anion-transporting polypeptide $1 \mathrm{~A} 2$ in blood-brain barrier drug penetration. Drug Metab Dispos 43:1008-1018.

Malhotra K, Safouris A, Goyal N, Arthur A, Liebeskind DS, Katsanos AH, SargentoFreitas J, Ribo M, Molina C, Chung JW, et al. (2019) Association of statin pretreatment with collateral circulation and final infarct volume in acute ischemic stroke patients: a meta-analysis. Atherosclerosis 282:75-79.

Mandery K, Bujok K, Schmidt I, Keiser M, Siegmund W, Balk B, König J, Fromm $\mathrm{MF}$, and Glaeser $\mathrm{H}$ (2010) Influence of the flavonoids apigenin, kaempferol, and 
quercetin on the function of organic anion transporting polypeptides $1 \mathrm{~A} 2$ and $2 \mathrm{~B} 1$. Biochem Pharmacol 80:1746-1753.

Mao J, Doshi U, Wright M, Hop CECA, Li AP, and Chen Y (2018) Prediction of the pharmacokinetics of pravastatin as an OATP substrate using plateable human hepatocytes with human plasma data and PBPK modeling. CPT Pharmacometrics Syst Pharmacol 7:251-258.

Miller DS and Cannon RE (2014) Signaling pathways that regulate basal ABC transporter activity at the blood- brain barrier. Curr Pharm Des 20:1463-1471.

Montaner J, Bustamante A, García-Matas S, Martínez-Zabaleta M, Jiménez C, de la Torre J, Rubio FR, Segura T, Masjuán J, Cánovas D, et al.; STARS Investigators (2016) Combination of thrombolysis and statins in acute stroke is safe: results of the STARS randomized trial (stroke treatment with acute reperfusion and simvastatin). Stroke 47:2870-2873.

Navrátilová L, Ramos Mandíková J, Pávek P, Mladěnka P, and Trejtnar F (2018) Honey flavonoids inhibit hOATP2B1 and hOATP1A2 transporters and hOATP mediated rosuvastatin cell uptake in vitro. Xenobiotica 48:745-755.

Ohtsuki S, Ikeda C, Uchida Y, Sakamoto Y, Miller F, Glacial F, Decleves X, Scherrmann JM, Couraud PO, Kubo Y, et al. (2013) Quantitative targeted absolute proteomic analysis of transporters, receptors and junction proteins for validation of human cerebral microvascular endothelial cell line hCMEC/D3 as a human bloodbrain barrier model. Mol Pharm 10:289-296.

Ose A, Kusuhara H, Endo C, Tohyama K, Miyajima M, Kitamura S, and Sugiyama Y (2010) Functional characterization of mouse organic anion transporting peptide 1a4 in the uptake and efflux of drugs across the blood-brain barrier. Drug Metab Dispos 38:168-176.

Römermann K, Fedrowitz M, Hampel P, Kaczmarek E, Töllner K, Erker T, Sweet DH, and Löscher W (2017) Multiple blood-brain barrier transport mechanisms limit bumetanide accumulation, and therapeutic potential, in the mammalian brain. Neuropharmacology 117:182-194.

Ronaldson PT and Bendayan R (2006) HIV-1 viral envelope glycoprotein gp120 triggers an inflammatory response in cultured rat astrocytes and regulates the functional expression of P-glycoprotein. Mol Pharmacol 70:1087-1098.

Ronaldson PT and Davis TP (2013) Targeted drug delivery to treat pain and cerebral hypoxia. Pharmacol Rev 65:291-314.

Ronaldson PT, Demarco KM, Sanchez-Covarrubias L, Solinsky CM, and Davis TP (2009) Transforming growth factor-beta signaling alters substrate permeability and tight junction protein expression at the blood-brain barrier during inflammatory pain. J Cereb Blood Flow Metab 29:1084-1098.

Ronaldson PT, Finch JD, Demarco KM, Quigley CE, and Davis TP (2011) Inflammatory pain signals an increase in functional expression of organic anion transporting polypeptide 1a4 at the blood-brain barrier. J Pharmacol Exp Ther 336:827-839.

Safar Z, Kis E, Erdo F, Zolnerciks JK, and Krajcsi P (2019) ABCG2/BCRP: variants, transporter interaction profile of substrates and inhibitors. Expert Opin Drug Metab Toxicol 15:313-328.

Sano Y, Mizuno T, Mochizuki T, Uchida Y, Umetsu M, Terasaki T, and Kusuhara H (2018) Evaluation of organic anion transporter 1A2-knock-in mice as a model of human blood-brain barrier. Drug Metab Dispos 46:1767-1775.

Shi L, Rocha M, Leak RK, Zhao J, Bhatia TN, Mu H, Wei Z, Yu F, Weiner SL, Ma F et al. (2018) A new era for stroke therapy: integrating neurovascular protection with optimal reperfusion. J Cereb Blood Flow Metab 38:2073-2091.

Shirasaka Y, Suzuki K, Nakanishi T, and Tamai I (2010) Intestinal absorption of HMG-CoA reductase inhibitor pravastatin mediated by organic anion transporting polypeptide. Pharm Res 27:2141-2149.

Takano J, Maeda K, Kusuhara H, and Sugiyama Y (2018) Organic anion transporting polypeptide 1a4 is responsible for the hepatic uptake of cardiac glycosides in mice. Drug Metab Dispos 46:652-657.

Thompson BJ, Sanchez-Covarrubias L, Slosky LM, Zhang Y, Laracuente ML and Ronaldson PT (2014) Hypoxia/reoxygenation stress signals an increase in organic anion transporting polypeptide 1a4 (Oatp1a4) at the blood-brain barrier: relevance to CNS drug delivery. J Cereb Blood Flow Metab 34:699-707.

van der Deure WM, Hansen PS, Peeters RP, Kyvik KO, Friesema EC, Hegedüs L, and Visser TJ (2008) Thyroid hormone transport and metabolism by organic anion transporter 1C1 and consequences of genetic variation. Endocrinology 149:5307-5314. Zhang L, Chopp M, Jia L, Cui Y, Lu M, and Zhang ZG (2009) Atorvastatin extends the therapeutic window for tPA to $6 \mathrm{~h}$ after the onset of embolic stroke in rats. J Cereb Blood Flow Metab 29:1816-1824.

Address correspondence to: Dr. Patrick T. Ronaldson, Department of Pharmacology, College of Medicine, University of Arizona, 1501 N. Campbell Ave., Tucson, AZ, 85724-5050. E-mail: pronald@email.arizona.edu 